\title{
Is the Birth PCR Still Necessary for HIV Exposed Newborns?
}

\author{
Fernando Bula, ${ }^{1}$ Mobeen H. Rathore ${ }^{2}$
}

\begin{abstract}
In 2009 the Unites States Public Health Service (USPHS) changed its recommendations for diagnostic testing of HIV exposed infants. However, barriers for compliance to testing remain. We evaluated the compliance with the 2009 USPHS recommendation at our center. A total of $244 \mathrm{HIV}$ exposed infants were identified from 2009 to 2012. HIV DNA PCR was done in less than 48 hours of life in $216(90.7 \%)$ infants, between 14-21 days in 143 (60.1\%). We believe it remains important to perform HIV testing at birth especially when testing at 14 to 21 days of life cannot be assured.
\end{abstract}

\section{Introduction}

The mother to child transmission (MTCT) of HIV in the United States has been reduced to $<1 \%$ with appropriate recommended preventive measures that include HIV screening of all pregnant women in the first and third trimester of pregnancy, use of antiretroviral

\footnotetext{
${ }^{1}$ Assistant Professor, Department of Pediatric, University of South Dakota, Sioux, Falls, SD

${ }^{2}$ Professor and Director, University of Florida Center for HIV/AIDS, Research, Education and Service (UF CARES) Associate Chairman, Department of Pediatric, University of Florida
}

\section{Date of Submission: 30-8-2016}

Date of Acceptance for Publication: 26-10-2016

Conflict of Interest: None

Funding Source: None

\section{Contribution}

All Authors have contributed in Study Design, Data Collection, Data Analysis, Data Interpretation, Manuscript Writing and Approval. regimen during pregnancy, cesarean deliveries when appropriate, avoidance of breast feeding, use of antiretroviral medication during labor and delivery and in the neonate in the first six weeks of life. ${ }^{1}$ Despite these recommendations, barriers to prevention of MTCT still exist. $^{2}$ It is important to follow the protocol for determination of HIV status in HIV exposed infants in order to determine as soon as possible if the infant is infected or uninfected.

This study aims to evaluate the compliance to most recent 2009 United Public Health Service (USPHS) recommendations for diagnostic testing infants born to HIV infected mothers.

\section{Patients and Methods}

We performed a retrospective analysis of records of all HIV infected pregnant women and HIV-exposed infants followed at the University of Florida Center for HIV/AIDS Research, Education and Service (UFCARES) between January $1^{\text {st }} 2009$ and December $31^{\text {st }}$ 2012. The dates and the results of HIV DNA PCR and HIV antibody tests were collected. We calculated the mean and median ages of infants at the time of HIV DNA PCR and HIV ELISA test.

\section{Results}

A total of 244 HIV exposed infants were identified in the four-year period between 2009 and 2012. Five infants were excluded from the study. One infant was diagnosed with HIV at four months of age because mother was diagnosed after the birth of the child. This infant was seen at UF CARES at the time of his first HIV test at four months of age. A second infant died at two months of age due to complications of prematurity, this infant had three negative DNA PCRs, and no records were found for three infants born to HIV 
infected pregnant women who were followed at UF CARES at some time during their pregnancy. These three infants were never followed at UF CARES. These five infants were excluded from further analysis.

The data for the remaining 239 infants were further analyzed.HIV DNA PCRs were done within 48 hours of birth in 216 infants $(90.7 \%)$, between 14 and 21 days in $143(60.1 \%)$ infants, between 28 to 35 days in $63(26.5 \%)$ infants and in $122(51.1 \%)$ infants between 16 to 20 weeks of age. All of these tests were negative. A total of 238 (99.5\%) infants had their first HIV DNA PCR test at a mean age of three days and a median of one day of life ( $1-226$ days). A total of $234(97.9 \%)$ infants had the second test at a mean age of 25 days and a median age of 20 days of life (2-464 days). HIV antibody ELISA tests were done after 18 months of age in 181 infants $(71.8 \%)$ and all were reported as negative.

\section{Discussion}

The current USPHS guidelines recommend that the birth HIV diagnostic test for an infant born to an HIV infected mother is optional and first HIV test should be done between 14 to 21 days of age. ${ }^{3}$ However, review of newborn testing of HIV exposed infants at UF CARES showed that only $60 \%$ of the HIV exposed infants returned for testing at 14 to 21 days of age. On the other hand almost $91 \%$ of the infants were tested for HIV infection within the first 48 hours of life. Based on our review of the data at UF CARES, we believe that a birth HIV DNA PCR test is still necessary at our center since recommended testing at 14 to 21 days of life has poor adherence and cannot be assured. In 2014 there were 6 confirmed mother to child transmission of HIV infection in Florida. In five of these six infants
HIV infection was diagnosed at birth with HIV DNA PCR done within the first 48 hours of life. In the sixth infant the birth HIV DNA PCR was negative. The first HIV DNA PCR in this infant was positive at 2 months of age.

Early diagnosis of HIV infection in the newborn is important for appropriate management, including early treatment and prophylaxis for opportunistic infections. ${ }^{4}$ Based on our data and diagnosis of perinatal HIV infection in Florida with birth diagnostic HIV testing we recommend that birth HIV DNA PCR should not be abandoned for making an early diagnosis of perinatal HIV infection. We recommend that birth HIV testing should be continued. The 2009 USPHS guidelines allow for birth testing for HIV of the newborn and this should be continued.

\section{References}

1. American Academy of Pediatrics. Red Book: 2012 Report of the Committee on Infectious Diseases. Pickering LK, ed. 29th ed. Elk Grove Village, IL: American Academy of Pediatrics, 2012.

2. Kline MV. Disparity between pediatricians' knowledge and practices regarding perinatal human immunodeficiency virus counseling and testing. Pediatrics, 2003 Nov; 112 (5): e367.

3. Panel on Antiretroviral Guidelines for Adults and Adolescents. Guidelines for the use of antiretroviral agents in HIV-1 infected adults and adolescents. Department of Health and Human Services. Available at: http://aidsinfo.nih.gov/contentfiles/lvguidelines/Adultan dAdolescentGL.pdf

Diagnosis of HIV infections in Infants and Children $(7 / 2 / 2013)$

4. Read JS. Committee on Pediatric AIDS. American Academy of Pediatrics. Diagnosis of HIV-1 infection in children younger than 18 months in the United States. Pediatrics, 2007 Dec; 120 (6): e1547-62. 